\title{
Efektifitas Pemuridan KEKAL dalam Membimbing Gereja Menuju Kedewasan Rohani
}

\author{
Orles \\ Sekolah Tinggi Teologi Kalimantan \\ Korespondensi: orles.yonatan@gmail.com
}

\begin{abstract}
Abstrak
Gereja adalah persekutuan orang-orang percaya yang dikuduskan oleh Allah dan bersekutu di dalam nama Yesus. Gereja didirikan oleh Tuhan Yesus. Oleh karena itu, pelayanan terhadap gereja tidak boleh diabaikan. Pertumbuhan jemaat kepada kedewasaan rohani harus menjadi fokus pelayanan gereja. Pemuridan Kelompok Kecil Alkitab (KEKAL) adalah salah satu strategi Gereja Baptis Anugerah Pontianak untuk membimbing jemaat menuju kedewasaan rohani. Permasalahannya adalah belum ada usaha untuk mengevaluasi keefektifan pelayanan melalui pemuridan KEKAL dalam membimbing jemaat bertumbuh dewasa secara rohani. Oleh sebab itu, tujuan penelitian ini adalah untuk melihat efektifitas pemuridan KEKAL dalam membimbing jemaat bertumbuh. Adapun metode penelitian yang digunakan dalam penelitian ini adalah deskriptif-kuantitatif. Pengumpulan datanya dilakukan dengan menggunakan angket tertutup. Melalui penelitian ini ditemukan hasil bahwa program pemuridan KEKAL berperan secara efektif dalam membimbing jemaat menuju kedewasaan rohani. Strategi pemuridan kelompok kecil ini dapat menjadi salah satu strategi bagi gereja untuk membimbing anggota jemaat agar dewasa di dalam Kristus.
\end{abstract}

Kata kunci: pemuridan, KEKAL, gereja, kedewasaan rohani

\begin{abstract}
The church is a collection of believers sanctified by God and allied in the name of Jesus. The church was founded by the Lord Jesus. Therefore, service to the church must not be ignored. Congregational growth to spiritual maturity must be the focus of church service. Discipleship of Small Bible Groups (KEKAL) is one of the strategies of the Pontianak Anugerah Baptist Church to guide the congregation towards spiritual maturity. The problem is that there has been no attempt to evaluate the effectiveness of ministry through KEKAL discipleship in guiding congregations to grow spiritually mature. Therefore, the purpose of this study is to see the effectiveness of KEKAL discipleship in guiding the church to grow. The research method used in this research is descriptivequantitative. The data collection is done by using a closed questionnaire. Through this research, it was found that the KEKAL discipleship program had an effective role in guiding the church to spiritual maturity. This small group discipleship strategy can be one of the strategies for the church to guide church members to mature in Christ.
\end{abstract}

Keywords: discipleship, KEKAL, church, spiritual maturity 


\section{PENDAHULUAN}

Charles G. Ward menulis tentang gereja bahwa gereja adalah Tubuh Kristus, yaitu persekutuan orang-orang tebusan Tuhan yang di dalamnya Ia menjadi kepala. ${ }^{1}$ Adapun Michael Griffiths menjelaskan bahwa "tubuh merupakan kata yang paling umum digunakan untuk menggambarkan gereja." ${ }^{2}$ Sedangkan Harun Hadiwijono berpendapat bahwa gereja adalah persekutuan orang kudus. ${ }^{3}$ Sementara Charles C. Ryrie, dengan mengutip pengakuan iman Baptis, menuliskan:

Gereja adalah suatu kumpulan orang-orang kudus yang kelihatan, yang dipanggil dan dipisahkan oleh Firman dan Roh Allah, untuk memberikan pengakuan iman yang kelihatan tentang Injil setelah mereka dibaptis ke dalam iman tersebut (XXXIII). ${ }^{4}$

Dari beberapa pengertian tentang gereja atau jemaat dapat disimpulkan bahwa gereja adalah kumpulan orang-orang percaya yang dikuduskan oleh Allah dan bersekutu di dalam nama Yesus. Oleh sebab itu pelayanan terhadap gereja tidak boleh dianggap remeh atau diabaikan. Berdasarkan Amanat Agung Tuhan Yesus dalam Matius 28:20a, gereja perlu mendapat perhatian yang serius. Gereja perlu diajar dan dibina agar bertumbuh menuju kedewasaan rohani. Penulis surat Ibrani memberitahukan penerima surat bahwa mereka harus meninggalkan azas-azas pertama dari ajaran tentang Kristus dan beralih kepada perkembangannya yang penuh (Ibr. 6:1a).

Agar anggota jemaat bertumbuh menuju kearah kedewasaan rohani, Gereja Baptis Anugerah Pontianak membuat dan melakukan program pelayanan untuk membimbing anggota gereja bertumbuh. Satu dari beberapa kegiatan yang diprogramkan untuk membimbing jemaat bertumbuh secara rohani adalah pemuridan

${ }^{1}$ Charles G. Ward, Buku Pegangan Pelayanan (Persekutuan Pembaca Alkitab, 1995), 63

${ }^{2}$ Michael Griffiths, Gereja dan Panggilannya Dewasa Ini (Jakarta: BPK Gunung Mulia, 1991), 25.

${ }^{3}$ Harun Hadiwijono, Iman Kristen (Jakarta: BPK Gunung Mulia, 2007), 380.

${ }^{4}$ Charles C. Ryrie, Teologi Dasar 2 ( Yogyakarta: Yayasan ANDI, 1992), 187. melalui Kelompok Kecil Alkitab (KEKAL), yang oleh gereja lain disebut Kelompok Sel (KOMSEL).

Program pemuridan KEKAL sesungguhnya sudah berjalan cukup lama di Gereja Baptis Anugerah Pontianak. Tetapi sempat berhenti beberapa waktu lamanya oleh karena dianggap kurang efektif. Setelah program ini dihentikan, muncullah beberapa persoalan seperti lambannya pertumbuhan jemaat baik secara kuantitas maupun secara kualitas. Hal ini ditunjukkan dengan tidak adanya pertambahan anggota jemaat baru, perpindahan beberapa anggota jemaat, dan anggapan bahwa kegiatan pelayanan tersebut memboroskan waktu dan dana. Oleh sebab itu, program pemuridan KEKAL ini dilanjutkan kembali. Tetapi permasalahan yang terjadi selama ini adalah belum pernah ada penelitian yang secara khusus meneliti sejauhmana efektifitas program pemuridan KEKAL dalam membimbing gereja menuju kedewasaan rohani. Oleh sebab itu, tujuan dari penelitian ini adalah untuk mengetahui efektifitas program pemuridan KEKAL ini dalam membimbing jemaat Gereja Baptis Anugerah Pontianak untuk bertumbuh menuju kedewasaan rohani.

\section{TINJAUAN PUSTAKA}

\section{Pemuridan KEKAL}

Pemuridan adalah suatu proses pembinaan yang dilakukan oleh guru kepada murid. Dengan kata lain, seorang murid yang belajar adalah seseorang yang memberikan kepercayaan sepenuhnya untuk diajar, dididik dan dilatih oleh seorang guru. Menurut Rick Warren: "Pemuridan yaitu proses menjadi serupa dengan Kristus." ${ }^{5}$ Di dalam Alkitab, dikatakan bahwa orang percaya adalah identik atau sama dengan murid Kristus. Hal ini dapat dilihat di dalam Kitab Kisah Para Rasul, 6:1, 2, 7; 11:26; 14:20, 22 dan 15:10. Ayat-ayat tersebut menjelaskan bahwa para pengikut Yesus disebut orang percaya dan murid secara bergantian. Jadi dapat

${ }^{5}$ Rick Warren, The Purpose Driven Life (Malang: Gandus Mas, 2005), 199. 
disimpulkan bahwa setiap orang yang mengaku percaya kepada Yesus, adalah murid Yesus.

Mengenai kelompok kecil, Jimmy Long menjelaskan bahwa di dalam "Kitab Perjanjian Lama maupun Perjanjian Baru, Allah memakai kelompok kecil dalam mewujudkan rencana-Nya, ... sebenarnya kelompok kecil telah dimulai sesudah penciptaan." 6 Selanjutnya di dalam Perjanjian Baru, Jimmy Long juga mengutarakan bahwa "doa Yesus untuk murid-muridNya (Yoh. 17) dapat dimengerti bahwa Yesus adalah pemimpin kelompok kecil." ${ }^{7}$ Warren S. Benson menulis bahwa kelompok kecil ini sangat penting dan bermanfaat dalam membentuk murid-murid Kristus menuju kedewasaan secara rohani. $^{8} \quad$ Jadi dapat disimpulkan bahwa pemuridan sangat efektif untuk membimbing anggota jemaat bertumbuh menuju kedewasaan rohani dan pemuridan ini dapat dilakukan melalui kelompok kecil. Alasannya, karena di dalam kelompok kecil setiap anggota dapat saling berbagi pengalaman dalam kelompok melalui kesaksian dan didalamnya ada pengajaran firman Tuhan untuk pertumbuhan setiap anggota.

Program pemuridan di Gereja Baptis Anugerah Pontianak dikenal dengan pemuridan KEKAL. Pemuridan KEKAL adalah program induk Gereja Baptis Anugerah Pontianak yang berkesinambungan untuk membimbing dan mengantar anggota gereja supaya bergabung dalam kelompok kecil Alkitab serta bertumbuh bersama secara rohani. Kegiatan yang dilakukan dalam KEKAL adalah belajar Firman Tuhan, berdoa, dan beribadah bersama. Didalamnya juga diadakan diskusi tentang pokok-pokok penting yang berhubungan dengan keperluan kelompok dan mengadakan pelatihan untuk pemimpin kelompok kecil Alkitab agar bertumbuh. ${ }^{9}$

Adapun peran dari pemuridan KEKAL dalam membimbing gereja menuju kedewasaan

${ }^{6}$ Jimmy Long, Buku Pegangan Pemimpin Kelompok Kecil (Jakarta: PERKANTAS, 1994), 14.

${ }^{7}$ Ibid., 15.

${ }^{8}$ Warren S. Benson, Pedoman Lengkap untuk Kaum Muda (Bandung: Kalam Hidup, 1999), 347.

${ }^{9}$ Ronny Welong, Program Pelayanan Gereja Baptis Anugerah Pontianak (Pontianak: GB Anugerah, 2005 2010), 9. rohani ada dua, yaitu: Pertama, mengajarkan doktrin Alkitab yang benar. Suhento Liauw menuliskan bahwa kebenaran Alkitab adalah sesuatu yang layak untuk dicari bahkan dikejar karena Alkitab adalah firman Allah."10 Oleh karena Alkitab adalah kebenaran yang menyatakan tentang eksistensi Allah, maka setiap pemimpin pemuridan KEKAL harus mengajarkan doktrin Alkitab yang benar. Tujuannya adalah supaya setiap anggota jemaat dapat bertumbuh dan menjadi dewasa secara rohani, serta memiliki pengetahuan yang benar tentang firman Allah. Dengan mengajarkan kebenaran Alkitab secara benar, setiap anggota jemaat tahu bahwa dirinya telah masuk dalam komunitas orang Kristen sejati dan murid Kristus sejati. Adapun yang dimaksud dengan komunitas orang Kristen sejati adalah sekelompok orang percaya yang setia dan taat dalam suatu pengajaran firman Tuhan dan dalam persekutuan, seperti pada jemaat mulamula (Kis. 2:41-47). Arif Santoso menulis:

\section{Seorang Kristen sejati berarti telah menerima dengan iman karya keselamatan Yesus Kristus dan hidup dalam persekutuan yang erat secara pribadi dengan-Nya, serta menjadi murid Tuhan dan tekun dalam pengajaran Tuhan dan persekutuan orang percaya. ${ }^{11}$}

Selanjutnya disebutkan juga bahwa "orang Kristen sejati memiliki iman yang menyelamatkan, yakni iman yang bersifat obyektif karena bersandarkan pada kesaksian dan fakta Injil." 12 Berdasarkan keadaan jemaat mula-mula (Kis. 2:41-47) dapat diketahui bahwa ada ciri-ciri dari komunitas orang Kristen sejati, yaitu: Pertama, tekun dalam pengajaran firman Tuhan. Alkitab adalah sumber utama yang dapat memberikan pertumbuhan rohani orang percaya. Rasul Petrus mengatakan bahwa sama seperti seorang bayi yang baru lahir yang membutuhkan air susu yang murni untuk pertumbuhannya, demikian juga orang percaya membutuhkan firman Tuhan sebagai susu yang

\footnotetext{
${ }^{10}$ Suhento Liauw, Doktrin Alkitab Alkitabiah (Jakarta: GBII GRAPHE, 1997), iv.

${ }^{11}$ Arif Santoso, Lazarus L., ST. Toenioe dan Soleman ND, The God Way Handbook, t.t, 157-158.

${ }^{12}$ Ibid., 160.
} 
murni untuk pertumbuhan rohaninya (1 Pet. 2:2). Supaya setiap orang yang tekun dalam pengajaran Firman Tuhan dapat bertumbuh, maka pengajaran itu harus diwujudkan dalam perbuatannya. Menurut Obaja $\mathrm{T}$ Setiawan firman Tuhan yang dikhotbahkan harus dicatat, direnungkan, dilakukan dan diceritakan. ${ }^{13}$ Jadi, untuk bertumbuh menuju kedewasaan rohani, maka setiap orang percaya harus hidup dengan tekun dalam pengajaran Firman Tuhan melalui kesetiaan dalam membaca, merenungkan, melakukan, dan menceritakan firman Tuhan kepada orang lain. Kedua, hidup dalam persekutuan doa. Peter Wagner menuliskan, "pada dasarnya doa adalah suatu hubungan. Melalui doa kita tinggal di dalam Allah. Doa menarik kita masuk ke dalam keakraban dengan Bapa. Doa adalah hubungan pribadi." ${ }^{14}$ Dapat disimpulkan bahwa doa adalah nafas hidup bagi rohani orang percaya. Untuk dapat bertumbuh menjadi dewasa secara rohani, setiap anggota jemaat harus hidup dalam doa. Ketiga, pribadi yang bersaksi. Jemaat mula-mula memberikan contoh yang jelas melalui kesaksian hidup mereka yang menjadi berkat bagi semua orang. Keempat, pribadi yang rela berkorban. Teladan sempurna dalam hal rela berkorban adalah Allah. Alkitab menginformasikan bahwa oleh karena kasih-Nya yang begitu besar akan dunia ini, Allah rela mengorbankan Putra tunggal-Nya untuk menggantikan posisi manusia yang seharusnya dihukum mati di kayu salib. Rasul Paulus mendorong jemaat Korintus untuk memiliki kerelaan berkorban (2 Kor. 8:12-14).

Sedangkan yang dimaksud dengan murid Kristus sejati adalah setiap orang yang telah mengaku dengan mulut dan percaya di dalam hatinya bahwa Yesus Kristus adalah Tuhan dan Juruselamatnya. Ciri-ciri murid Kristus sejati adalah: Pertama, memiliki hati mengasihi jiwajiwa. Sepanjang pelayanan Tuhan Yesus di muka bumi selama tiga setengah tahun, selalu diwarnai dengan hati yang penuh belas kasihan ketika melihat jiwa-jiwa yang akan binasa. Murid Kristus sejati akan menjangkau jiwa-jiwa yang

\footnotetext{
${ }^{13}$ Obaja T. Setiawan, Kelompok Sel: Prinsip 12 (Jakarta: Metanoia, t.t), 34.

${ }^{14}$ J. Peter Wagner, Gereja Yang Berdoa (Yogyakarta: ANDI, 1993), 30.
}

belum mengenal Tuhan dengan penuh belas kasihan sehingga banyak orang akan diselamatkan. Inti dari pemuridan KEKAL adalah adanya gaya hidup yang saling mengasihi antar sesama orang percaya dan mengasihi juga orang-orang yang belum mengenal Tuhan. Ciri kedua, memiliki iman yang kuat. Gerald R. McDermott menuliskan: “... kerohanian sejati adalah suatu keyakinan yang kuat, baik dalam pikiran maupun hati, bahwa kebenarankebenaran ilahi yang diakui oleh iman Kristen adalah benar." 15 Iman seorang murid dalam kelompok kecil akan sangat memengaruhi multipikasi kelompok selanjutnya. Kedewasaan iman seorang murid Kristus sejati ditandai dengan visi untuk menjadi pelipatgandaan murid agar kelompok yang diajar dapat membentuk kelompok sendiri. Ciri ketiga, siap bayar harga. Alkitab menceritakan bahwa ada harga yang harus dibayar sebagai murid Yesus sejati. Rasul Paulus adalah satu dari sekian banyak murid Kristus yang mengenakan karakter Kristus dalam melayani (2 Kor. 11:23; 1 Pet. 1:18). Berdasarkan teladan Kristus dan Paulus tersebut, maka setiap orang percaya yang adalah murid Kristus juga harus siap bayar harga dalam pekerjaan Tuhan dengan cara siap mengorbankan waktu, tenaga, harta, dan bahkan nyawanya untuk Tuhan. Keempat, memiliki karakter Kristus. Paulus mendorong jemaat Filipi untuk meneladani kerendahan hati dan ketaatan Kristus (Fil. 2:6-8). Gambaran dari karakter Kristus dapat dilihat dari buah-buah roh (Gal. 5:22-23a).

Peran kedua, melatih murid Kristus dengan prinsip alkitabiah. Prinsip melatih murid Kristus yang alkitabiah misalnya melalui melatih dengan pola Yesus dan pola rasul Paulus. LeRoy Eims mengutarakan tentang pola Yesus, bahwa "Dalam melatih murid ini ditemukan tiga prinsip, yaitu prinsip pemilihan, prinsip hubungan yang akrab dan prinsip pembinaan." 16 Untuk membimbing anggota jemaat agar bertumbuh dewasa secara rohani, hidupnya menjadi kesaksian, dan dapat menghasilkan

\footnotetext{
${ }^{15}$ Gerald R. McDermott, Mengenal 12 Tanda Kerohanian Sejati (Yogyakarta: ANDI 2001), 162.

${ }^{16}$ LeRoy Eims, Pemuridan Seni yang Hilang (Bandung: Lembaga Literatur Baptis, 1978), 23-32.
} 
murid-murid bagi Kristus, maka pola Yesus ini sangat tepat untuk dilakukan. Eddy Leo menuliskan tentang pola Yesus demikian "Pemuridan yang dilakukan Tuhan Yesus adalah dengan cara: mengajar, melatih dan membentuk mental dan karakter setiap murid." Berdasarkan pola pemuridan yang dilakukan oleh Tuhan Yesus, dapat dipahami bahwa mengajar lebih bersifat teori, yaitu memperdalam pengetahuan setiap murid Kristus tentang Firman Tuhan. Kemudian melatih cenderung kepada keteladanan yang didalamnya ada prinsip pemilihan, prinsip hubungan yang akrab dan prinsip pembinaan. Setiap murid dapat melihat dan mempraktikkan langsung; bagaimana Yesus mengajar dan melatih ke-12 murid dan banyak orang, melalui perkataan dan perbuatan-Nya. Selain itu, melatih dengan pola Paulus juga perlu diterapkan dalam pemuridan. J. Oswald Sanders mengatakan bahwa "Paulus sangat menginginkan anak didiknya tumbuh menjadi pelayan Kristus yang baik." ${ }^{18}$ Adapun pola yang dilakukan oleh Paulus dalam melatih anak didiknya, adalah mengajar, memberi dorongan, dan menjadikan dirinya sebagai teladan iman bagi Timotius (1 Kor. 11:1; 4:12). Hal ini memberikan pemahaman bahwa pengajaran tidak hanya lewat teori saja, tetapi melalui teladan hidup dalam seluruh aspek kehidupan sehari-hari juga sangat penting bagi murid Kristus. Pola yang diterapkan oleh Paulus terhadap Timotius dapat dikatakan berhasil. Hal ini dapat dilihat dari tulisan Roy Robertson: "seorang Timotius memiliki beban yang sama seperti orang tua rohaninya." ${ }^{19}$ Dari pernyataan tersebut, dapat diketahui bahwa prinsip kedua dari pola pelatihan Paulus adalah menjadikan dirinya sebagai bapa rohani Timotius, sehingga dalam proses pelatihan, ada hubungan yang akrab, seperti seorang ayah terhadap anaknya. (Jakarta: Metanoia, 2005), 103-104.

${ }^{18}$ J. Oswald Sanders, Kemuridan Rohani (Batam Center: Gospel Press, 2002), 197.

${ }^{19}$ Roy Robertson, Pemuridan dengan Prinsip Timotius (Yogyakarta: 1995), 98.

\section{Kedewasaan Rohani}

Kedewasaan rohani jemaat adalah capaian yang diharapkan melalui pemuridan KEKAL di Gereja Baptis Anugerah Pontianak. Kedewasaan dapat diartikan sebagai "keadaan pertumbuhan dan perkembangan yang lengkap melalui proses alamiah", atau yang berhubungan dengan keadaan perkembangan penuh sebagai seorang yang dewasa dalam usia." 20 Tanggung jawab gereja adalah membimbing setiap anggotanya bertumbuh menuju kedewasaan secara rohani. Hal ini selaras dengan apa yang dituliskan Rasul Paulus dalam Efesus 4:13.

Beberapa tanda dari seseorang yang sudah dewasa rohani, diantaranya: tanda pertama, memiliki pengetahuan yang benar tentang firman Tuhan. Gerald R. McDermott menulis demikian: "Perjanjian Baru menjelaskan bahwa kerohanian sejati melibatkan pengetahuan baru, pengertian baru. Ada unsur kognitif dalam karya anugerah." ${ }^{21}$ Kedewasaan rohani ini menjadi pokok doa Paulus bagi jemaat Filipi (Flp. 1:9) dan pokok teguran Paulus bagi jemaat Galatia (Gal. 1:6-7). Warren W. Wiersbe mengatakan: "orang Kristen yang dewasa tidak mudah diombang ambingkan oleh suatu pengajaran agama baru, tetapi dapat mengenali doktrin palsu dan menjauhkan diri dari padanya". ${ }^{22}$

Tanda kedua, memiliki persekutuan yang intim dengan Allah. Sejak Allah menciptakan manusia dan menempatkannya di taman Eden, sebenarnya Allah menghendaki ciptaan-Nya itu bersekutu dengan-Nya. Tetapi karena manusia tidak taat kepada perintah Allah, manusia itu jatuh ke dalam dosa. Karena manusia itu telah berdosa, maka Allah yang kudus mengusir manusia itu dari hadapan-Nya. Tetapi karena begitu besar kasih-Nya kepada manusia, maka Allah mengutus Yesus Kristus Putra tunggal-Nya untuk mencari dan memulihkan persekutuan antara Allah dengan manusia ciptaan-Nya. Tindakan untuk memulihkan persekutuan itu

\footnotetext{
${ }^{20}$ Rick C. Howard, Pendewasaan Kristen (Malang: Gandum Mas, 1982), 18.

${ }^{21}$ Gerald R. McDermott, Mengenal 12 Tanda

Kerohanian Sejati (Yogyakarta: ANDI, 2001), 229.

${ }^{22}$ Warren W. Wiersbe, Kaya di dalam Kristus (Malang: Gandum Mas, 1982), 120 
adalah inisiatif Allah, dan telah dilakukan oleh Allah dengan jalan menjadikan Kristus sebagai korban yang harus mati di salib. Kepada jemaat Korintus, Paulus dengan sangat jelas menulis demikian: "Sebab kamu telah dibeli dan harganya telah lunas dibayar: karena itu muliakanlah Allah dengan tubuhmu" (1 Kor. 6:20). Dalam Kitab Mazmur 91, janji-janji yang Allah berikan dapat menjadi kenyataan dalam hidup, jika orang percaya tinggal dalam hadiratNya.

Tanda ketiga, memiliki ketaatan terhadap firman Allah. Paulus mendorong jemaat di Efesus agar menaati tuan yang di dunia sama seperti kepada Kristus (Ef. 6:5) Ketaatan seorang hamba kepada tuan atau majikan merupakan tanggung jawab yang mudah untuk dilakukan, jika sebagai hamba setiap orang percaya memandang kepada Kristus yang adalah Tuan sesungguhnya. Tunduk dan taat karena tidak ingin mengecewakan dalam melakukan kewajiban dan dengan satu keinginan, dimaksudkan memberikan pelayanan penuh dan menyenangkan. ${ }^{23}$ Orang percaya yang memiliki pengetahuan yang benar tentang firman Tuhan akan senantiasa taat terhadap kebenaran firman Tuhan.

Tanda keempat, menyampaikan kebenaran dengan kasih dan jujur. Seorang percaya yang bertumbuh dalam komunitasnya pasti akan berhubungan dengan sesama saudara seiman. Kualitas hubungannya tersebut akan teruji pada waktu menyampaikan kebenaran dalam kasihnya terhadap sesama. Alkitab mengingatkan orang Kristen agar jujur mengatakan kebenaran kepada sesama (Ams. 27:5-6; Kel. 20:16; Mat. 5:37). Hal ini merupakan tanda kedewasaan rohani seseorang.

Tanda kelima, memiliki kasih yang holistik. Kasih yang holistik adalah kasih secara vertikal dan horizontal. Secara vertikal, artinya orang percaya mengasihi Allah dan secara horizontal maksudnya orang percaya mengasihi sesama. Kasih secara vertikal adalah kasih kepada Allah. Alkitab menegaskan keutamaan kasih kepada Allah ini (Ul. 6:5; Mat. 22:37). Sedangkan kasih

\footnotetext{
${ }^{23}$ Jerry Autery, Surat Kiriman Penjara (Malang: Gandum Mas, t.t), 143.
}

secara horisontal adalah kasih terhadap sesama. Alkitab memerintahkan orang percaya agar mengasihi sesamanya (Im. 19:18; Mat. 22:39). Rasul Yohanes menegaskan bahwa kasih merupakan dasar yang sangat penting dalam membangun hubungan, baik kepada Allah maupun kepada sesama (1 Yoh. 4:7-8, 20). Senada dengan hal tersebut, Edy Fances mengutarakan:

\begin{abstract}
Kekuatan kasih Kristus juga menolong kita hidup kita mengasihi sesama manusia dengan motivasi dan tujuan yang benar. ... Mengasihi orangv lain dengan motivasi yang murni yaitu cinta kasih yang telah kita terima dari Kristus. Cinta kasih yang tanpa pamrih, penuh kemurahan, kebaikan dan rendah hati dan rela berkorban. Cinta kasih dengan tujuan membangun orangv lain, menolong dengan perbuatan yang vkonkrit, dan demi mendatangkan kebaikan dan keuntungan bagi orang lain tanpa mengharapkan balasan yang bersifat transaksional. ${ }^{24}$
\end{abstract}

Sementara Wactman Nee juga menegaskan tentang pentingnya membangun hubungan yang baik dengan sesama, mengatakan:

Kasih akan sesama saudara seiman merupakan dasar yang penting dalam kehidupan setiap pekerja Kristen, tetapi yang tidak kurang pentingnya adalah kasih akan sesama manusia, akan setiap orang. ${ }^{25}$

\section{METODE}

Metode Penelitian yang digunakan dalam penelitian ini adalah metode penelitian deskriptif-kuantitatif. Penelitian ini ingin mendeskripsikan efektifitas program pemuridan KEKAL dalam menumbuhkan kedewasaan rohani jemaat. Deskripsinya akan dilihat dari prosentase jawaban responden dan grafiknya.

Teknik pengumpulan data dilakukan melalui observasi lapangan dan angket dengan jawaban tertutup. Observasi dilakukan dengan cara melakukan pengamatan terhadap permasalahan yang terjadi di Gereja Baptis Anugerah Pontianak, yaitu masalah anggota jemaat yang

${ }^{24}$ Eddy Fances, Mengenal dan dikenal Allah (Jakarta: Yasinta, 2003), 108-109.

${ }^{25}$ Wactman Nee, Pekerja Kristus (Bandung: Kalam

Hidup, 1972), 28. 
belum dewasa secara rohani. Responden berjumlah 42 orang yang diambil secara acak dari para anggota KEKAL. Tempat penelitian adalah Gereja Baptis Anugerah Pontianak, Kalimantan Barat.

\section{HASIL DAN PEMBAHASAN}

Setelah data-data, yaitu angket yang berisikan daftar pertanyaan dan jawaban kepada 42 anggota pemuridan KEKAL dikembalikan oleh responden, selanjutnya data-data tersebut di analisa. Setelah dianalisa, peneliti membagikan keadaan responden dalam tiga katagori, yaitu: Usia, Tingkat Pendidikan dan Pekerjaan. Kemudian dipaparkan daftar pertanyaan dan jawaban responden ke dalam tabel berdasarkan kedua variabel dalam penelitian ini, yaitu: Pemuridan KEKAL dan Kedewasaan Rohani. Peneliti mulai dengan memaparkan keadaan responden dalam ketiga kategori sebagai berikut:

Tabel dan Grafik 1. Usia Responden

\begin{tabular}{|c|c|c|}
\hline Kategori Usia & $\begin{array}{c}\text { Jumlah } \\
\text { Responden }\end{array}$ & $\begin{array}{c}\text { Prosentase } \\
(\%)\end{array}$ \\
\hline 0 sampai 10 & 0 & $0 \%$ \\
\hline 11 sampai 20 & 11 & $26,5 \%$ \\
\hline 21 sampai 30 & 10 & $24 \%$ \\
\hline 31 sampai 40 & 17 & $40 \%$ \\
\hline 41 sampai 50 & 4 & $9,5 \%$ \\
\hline 51 keatas & 0 & $0 \%$ \\
\hline
\end{tabular}

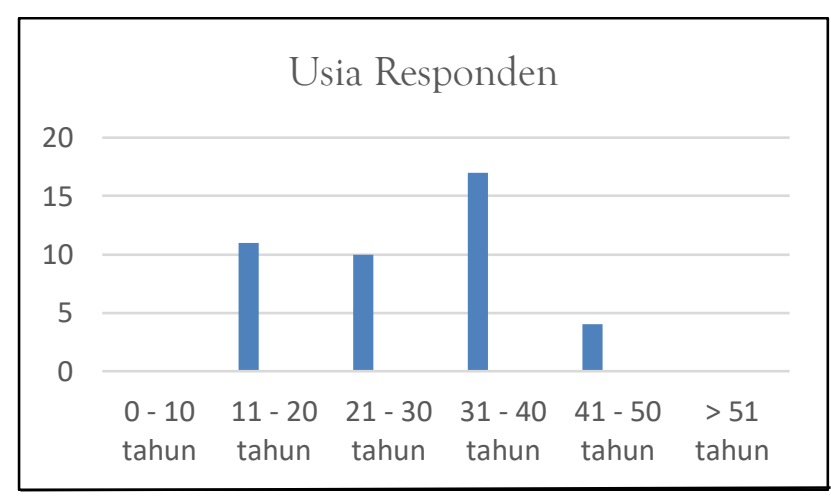

Berdasarkan tingkat usia responden pada tabel diatas, diketahui bahwa anggota pemuridan KEKAL Gereja Baptis Anugerah Pontianak didominasi oleh kelompok usia 31 sampai 40 tahun, yaitu berjumlah 17 orang (40\%). Tingkatan usia terbanyak ini menunjukkan bahwa anggota pemuridan Kelompok Kecil Alkitab di Gereja Baptis Anugerah Pontianak kebanyakan sudah berusia dewasa.

Tabel dan Grafik 2. Pendidikan Responden

\begin{tabular}{|c|c|c|}
\hline $\begin{array}{c}\text { Tingkat } \\
\text { Pendidikan }\end{array}$ & $\begin{array}{c}\text { Jumlah } \\
\text { Responden }\end{array}$ & $\begin{array}{c}\text { Prosentase } \\
(\%)\end{array}$ \\
\hline SD & 1 & $2,5 \%$ \\
\hline SMP & 15 & $36,5 \%$ \\
\hline SMA/Sederajat & 13 & $30,4 \%$ \\
\hline Diploma (D3) & 4 & $9,1 \%$ \\
\hline Sarjana (S1) & 9 & $21,5 \%$ \\
\hline
\end{tabular}

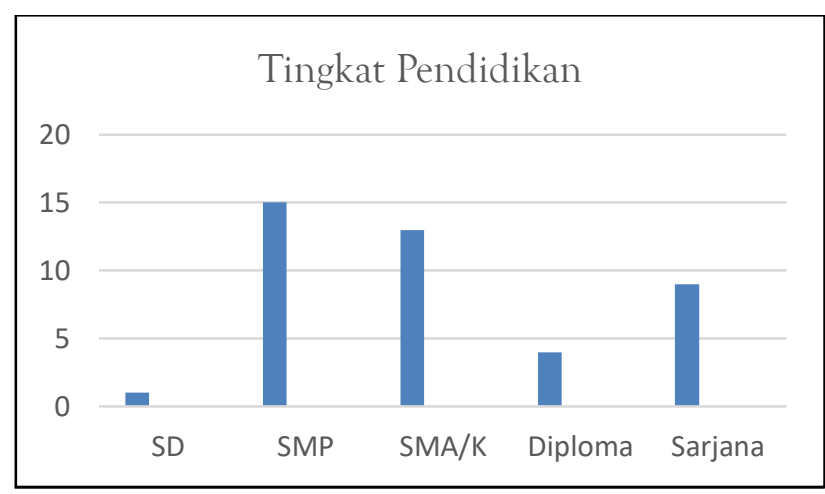

Dari tabel 2 tentang Latar Belakang Tingkat Pendidikan responden diatas, diketahui bahwa tingkat pendidikan anggota pemuridan KEKAL Gereja Baptis Anugerah Pontianak; itu terdiri dari lima tingkatan pendidikan. Anggota pemuridan KEKAL terbanyak, didominasi oleh jemaat yang berlatar pendidikan SMP, berjumlah 15 orang dengan $36.5 \%$. Untuk kedua terbanyak yaitu anggota yang berlatar pendidikan SMA, berjumlah 13 orang, dengan 30,4\%.

Tabel dan Grafik 3. Pekerjaan Responden

\begin{tabular}{|c|c|c|}
\hline Jenis Pekerjaan & $\begin{array}{c}\text { Jumlah } \\
\text { Responden }\end{array}$ & $\begin{array}{c}\text { Prosentase } \\
(\%)\end{array}$ \\
\hline Guru (PNS/Swasta) & 5 & $12 \%$ \\
\hline Buruh/Karyawan & 13 & $31 \%$ \\
\hline Perawat (PNS) & 2 & $5 \%$ \\
\hline Pelajar SMP - SMA & 8 & $19 \%$ \\
\hline Mahasiswa & 4 & $9 \%$ \\
\hline Ibu Rumah Tangga & 10 & $24 \%$ \\
\hline
\end{tabular}




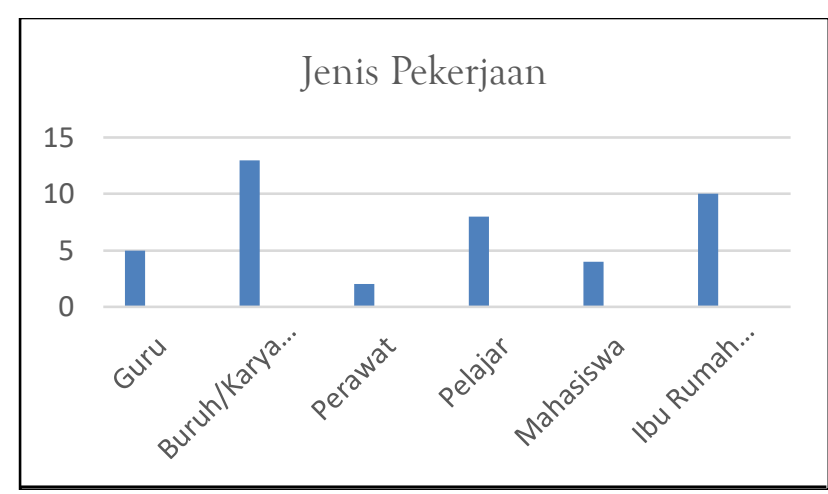

Mencermati data dalam tabel tentang jenis pekerjaan responden anggota pemuridan KEKAL Gereja Baptis Anugerah Pontianak, teridentifikasi bahwa kebanyakan responden bekerja sebagai buruh/karyawan sebanyak 13 orang (31\%), ibu rumah tangga sebanyak 10 orang (24\%), dan pelajar SMP dan SMA/Sederajat sejumlah 8 orang (19\%).

Selanjutnya dipaparkan daftar pertanyaan dan jawaban responden ke dalam tabel sebagai berikut:

Tabel. 4 Daftar Pertanyaan

Variabel Pemuridan KEKAL

\begin{tabular}{|c|c|c|c|}
\hline \multirow{2}{*}{ No } & \multirow{2}{*}{ Pertanyaan } & \multicolumn{2}{|c|}{ Jawaban } \\
\hline & & $\mathrm{Ya}$ & Tdk \\
\hline 1 & $\begin{array}{l}\text { Tahukah anda bahwa } \\
\text { setiap orang yang telah } \\
\text { mengaku percaya kepada } \\
\text { Yesus adalah murid Yesus? }\end{array}$ & 41 & 1 \\
\hline 2 & $\begin{array}{l}\text { Tahukah anda bahwa } \\
\text { sebagai murid Kristus, anda } \\
\text { harus bertumbuh menjadi } \\
\text { orang Kristen sejati dan } \\
\text { murid Kristus sejati, yaitu } \\
\text { dewasa secara rohani? }\end{array}$ & 42 & 0 \\
\hline 3 & $\begin{array}{l}\text { Tahukah anda, bahwa } \\
\text { untuk bertumbuh menjadi } \\
\text { dewasa; anda perlu } \\
\text { bimbingan, yaitu lewat atau } \\
\text { ikut pemuridan KEKAL? }\end{array}$ & 37 & 5 \\
\hline 4 & $\begin{array}{l}\text { Setelah ikut pemuridan } \\
\text { KEKA" ini, apakah anda } \\
\text { mengalami pertumbuhan } \\
\text { secara pengetahuan tentang } \\
\text { ajaran Alkitab yang benar? }\end{array}$ & 40 & 2 \\
\hline 5 & $\begin{array}{l}\text { Sebagai orang Kristen sejati } \\
\text { (dewasa), sadarkah bahwa }\end{array}$ & 41 & 1 \\
\hline
\end{tabular}

\begin{tabular}{|c|c|c|c|}
\hline & $\begin{array}{l}\text { anda harus: tekun dalam } \\
\text { pengajaran Firman, tekun } \\
\text { dalam persekutuan doa, } \\
\text { mau bersaksi, dan rela } \\
\text { berkorban untuk pekerjaan } \\
\text { Injil Kristus? }\end{array}$ & & \\
\hline 6 & $\begin{array}{l}\text { Sebagai murid Kristus sejati } \\
\text { (dewasa), sadarkah bahwa } \\
\text { anda harus: mengasihi jiwa- } \\
\text { jiwa yang belum mengenal } \\
\text { Tuhan, memiliki iman } \\
\text { yang kuat, siap bayar harga } \\
\text { dan memiliki karakter } \\
\text { Kristus? }\end{array}$ & 40 & 2 \\
\hline 7 & $\begin{array}{l}\text { Menurut anda, apakah } \\
\text { pemuridan KEKAL ini, } \\
\text { tepat dan bermanfaat } \\
\text { untuk membimbing jemaat } \\
\text { di Gereja Baptis Anugerah } \\
\text { Pontianak menuju kearah } \\
\text { kedewasaan rohani? }\end{array}$ & 39 & 3 \\
\hline 8 & $\begin{array}{l}\text { Jika kegiatan pemuridan } \\
\text { ini tepat dan bermanfaat, } \\
\text { apakah anda akan tetap } \\
\text { setia mengikuti kegiatan } \\
\text { pemuridan KEKAL ini, } \\
\text { dan mau mendukung } \\
\text { kegiatan ini lewat dana } \\
\text { (persembahan), tenaga dan } \\
\text { waktu anda? }\end{array}$ & 40 & 2 \\
\hline
\end{tabular}

Berdasarkan pertanyaan wawancara dan jawaban responden dalam tabel 4 diatas, dapat dideskripsikan sebagai berikut:

Dari 42 responden, yang menjawab "ya" untuk pertanyaan nomor 1 berjumlah 41 orang (98\%) dan yang menjawab "tidak" 1 orang (2 $\%)$ Ini artinya hampir semua responden mengetahui bahwa setelah mengaku percaya Yesus, dirinya adalah murid Kristus. Responden menyadari bahwa dirinya adalah seorang murid Kristus.

Dari 42 responden, yang menjawab "ya" untuk pertanyaan nomor 2 berjumlah 42 orang (100 \%) dan tidak ada yang menjawab "tidak." Ini artinya semua responden mengetahui bahwa sebagai murid Kristus dirinya harus menjadi orang Kristen sejati dan murid Yesus sejati, yaitu dewasa secara rohani di dalam Tuhan. 
Dari 42 responden, yang menjawab "ya" untuk pertanyaan nomor 3 , berjumlah 36 orang (86\%), dan yang menjawab "tidak" ada 6 orang (14\%). Ini artinya sebagian besar responden mengetahui bahwa untuk bertumbuh menjadi orang yang dewasa dirinya perlu bimbingan melalui pemuridan KEKAL. Mereka menyadari bahwa melalui pemuridan KEKAL responden bisa bertumbuh secara rohani. Meskipun demikian, masih ada beberapa responden yang merasa tidak perlu ikut pemuridan dengan jumlah 6 orang (14\%).

Dari 42 responden, yang menjawab "ya" untuk pertanyaan nomor 4 berjumlah 40 orang (95\%), dan yang menjawab "tidak" 2 orang (5 $\%)$ Ini artinya hampir semua responden mengaku bahwa dirinya mengalami pertumbuhan secara pengetahuan tentang ajaran atau dokrin Alkitab yang benar.

Dari 42 responden, yang menjawab "ya" untuk pertanyaan nomor 5 berjumlah 41 orang (98\%), dan yang menjawab "tidak" 1 orang (2 $\%)$ Ini artinya hampir semua responden meyadari bahwa sebagai orang Kristen sejati (dewasa), dirinya harus bertekun dalam pengajaran Firman, persekutuan doa, mau bersaksi, dan rela berkorban untuk pekerjaan Injil Kristus.

Dari 42 responden, yang menjawab "ya" untuk pertanyaan nomor 6 berjumlah 40 orang (95\%) dan yang menjawab "tidak" 2 orang (5 $\%)$. Ini artinya sebagai murid Kristus sejati (dewasa), responden menyadari bahwa dirinya harus mengasihi jiwa- jiwa yang belum mengenal Tuhan, memiliki iman yang kuat, siap bayar harga dan memiliki karakter Kristus.

Dari 42 responden, yang menjawab "ya" untuk pertanyaan nomor 7 berjumlah 39 orang (93\%), dan yang menjawab "tidak" 3 orang (7 $\%)$ Ini artinya hampir semua responden mengakui bahwa pelayanan pemuridan KEKAL tepat dan bermanfaat untuk membimbing anggota jemaat di Gereja Baptis Anugerah Pontianak menuju kearah kedewasaan rohani.

Dari 42 responden, yang menjawab "ya" untuk pertanyaan nomor 8 berjumlah 40 orang (95\%), dan yang menjawab "tidak" 2 orang (5 $\%)$. Ini artinya bahwa hampir semua responden sadar dan mau berkomitmen untuk tetap setia mengikuti kegiatan pemuridan KEKAL dan mau mendukung kegiatan ini lewat dana (persembahan), tenaga dan waktunya.

Tabel 5. Daftar Pertanyaan Wawancara Variabel : Kedewasaan Rohani

\begin{tabular}{|c|c|c|c|}
\hline \multirow{2}{*}{ No } & \multirow{2}{*}{ Pertanyaan } & \multicolumn{2}{|c|}{ Jawaban } \\
\hline & & $\mathrm{Ya}$ & $\mathrm{Tdk}$ \\
\hline 1 & $\begin{array}{l}\text { Maukah anda bertumbuh } \\
\text { menjadi orang yang dewasa } \\
\text { secara rohani? }\end{array}$ & 42 & 0 \\
\hline 2 & $\begin{array}{l}\text { Tahukah anda bahwa } \\
\text { dewasa secara rohani arti- } \\
\text { nya orang itu memiliki } \\
\text { pengertian yang benar dan } \\
\text { dalam tentang Alkitab? }\end{array}$ & 32 & 10 \\
\hline 3 & $\begin{array}{l}\text { Tahukah anda, bahwa } \\
\text { orang yang sudah dewasa } \\
\text { secara rohani, orang itu } \\
\text { memiliki hubungan yang } \\
\text { intim dengan Allah (ada } \\
\text { persekutuan secara pribadi } \\
\text { dengan Allah)? }\end{array}$ & 38 & 4 \\
\hline 4 & $\begin{array}{l}\text { Tahukah anda, bahwa } \\
\text { orang Kristen atau murid } \\
\text { Kristus yang sudah dewasa } \\
\text { secara rohani, taat } \\
\text { melakukan firman Allah? }\end{array}$ & 40 & 2 \\
\hline 5 & $\begin{array}{l}\text { Mengertikah anda, bahwa } \\
\text { sebagai orang Kristen atau } \\
\text { murid Kristus yang dewasa } \\
\text { secara rohani, anda harus } \\
\text { menyampaikan kebenaran } \\
\text { dengan kasih dan dengan } \\
\text { sikap jujur (tidak boleh } \\
\text { berbohong/berdusta). Jika } \\
\text { "ya" katakan "ya" dan jika } \\
\text { "tidak" katakan "tidak" }\end{array}$ & 42 & 0 \\
\hline 6 & $\begin{array}{l}\text { Tahukah anda, bahwa } \\
\text { sebagi orang Kristen atau } \\
\text { murid Kristus yang sudah } \\
\text { dewasa, anda harus } \\
\text { memiliki kasih yang } \\
\text { holistik (yaitu: terutama } \\
\text { Kasih kepada Allah, } \\
\text { kemudian kasih kepada } \\
\text { sesama manusia)? }\end{array}$ & 42 & 0 \\
\hline 7 & $\begin{array}{l}\text { Tahukah anda, bahwa } \\
\text { mengasihi Allah, itu harus }\end{array}$ & 41 & 1 \\
\hline
\end{tabular}




\begin{tabular}{|l|l|l|l|}
\hline & $\begin{array}{l}\text { dengan segenap hati, } \\
\text { segenap jiwa dan dengan } \\
\text { segenap akal budi kita? dan } \\
\text { mengasihi sesama tolok } \\
\text { ukurnya adalah seperti } \\
\text { anda mengasihi diri } \\
\text { sendiri? }\end{array}$ & & \\
\hline 8 & $\begin{array}{l}\text { Apakah dalam proses } \\
\text { pemuridan KEKAL ini, } \\
\text { anda merasa senang, dan } \\
\text { mengalami pertumbuhan } \\
\text { secara rohani? }\end{array}$ & 42 & \\
\hline
\end{tabular}

Berdasarkan pertanyaan wawancara dan jawaban responden dalam tabel 5 diatas, dapat dideskripsikan sebagai berikut:

Dari 42 responden, yang menjawab "ya" untuk pertanyaan nomor 1 berjumlah 42 orang (100 \%) dan tidak ada yang menjawab "tidak." Ini artinya semua responden menginginkan untuk bertumbuh menjadi dewasa di dalam Kristus. Seluruh responden menyadari bahwa dirinya perlu terus bertumbuh secara rohani.

Dari 42 responden, yang menjawab "ya" untuk pertanyaan nomor 2 berjumlah 32 orang (76 \%) dan yang menjawab "tidak" 10 orang (24\%). Ini artinya; walaupun mayoritas responden tahu, tapi masih banyak yang belum tahu bahwa orang yang dewasa secara rohani harus memiliki pengertian yang benar dan dalam tentang Alkitab.

Dari 42 responden yang menjawab "ya" untuk pertanyaan nomor 3 , berjumlah 38 orang (90\%), dan yang menjawab "tidak" 4 orang (10 $\%)$ Ini artinya sebagian besar responden mengetahui bahwa orang yang sudah dewasa secara rohani ditandai dengan memiliki hubungan yang intim dengan Allah. Meskipun demikian, ada beberapa responden yang tidak mengetahui keterkaitan kedewasaan rohani dengan adanya hubungan yang intim dengan Allah.

Dari 42 responden, yang menjawab "ya" untuk pertanyaan nomor 4 berjumlah 40 orang (95\%) dan yang menjawab "tidak" 2 orang (5 $\%)$. Ini artinya mayoritas responden mengetahui atau menyadari bahwa orang Kristen atau murid Kristus yang dewasa secara rohani harus taat dalam melakukan firman Allah.
Dari 42 responden, yang menjawab "ya" untuk pertanyaan nomor 5 berjumlah 42 orang (100\%) dan tidak ada yang menjawab "tidak." Ini artinya semua responden mengetahui bahwa sebagai orang Kristen atau murid Kristus yang dewasa dirinya harus berkata benar. Responden menyadari bahwa kejujuran dalam tutur kata merupakan karakter dari murid Kristus.

Dari 42 responden, yang menjawab "ya" untuk pertanyaan nomor 6 , berjumlah 42 orang (100 \%). Ini artinya semua responden tahu bahwa sebagai orang Kristen atau murid Kristus yang dewasa, dirinya harus memiliki kasih yang holistik yaitu kasih kepada Allah dan sesama. Responden menyadari bahwa kasih adalah karakteristik murid Kristus.

Dari 42 responden, yang menjawab "ya" untuk pertanyaan nomor 7 berjumlah 41 orang (98 \%) dan yang menjawab "tidak" 1 orang (2 $\%)$ Ini artinya hampir semua responden mengetahui bahwa sebagai orang Kristen atau murid Kristus yang dewasa, dirinya harus terutama mengasihi Allah dan dan juga sesama manusia.

Dari 42 responden, yang menjawab "ya" untuk pertanyaan nomor 8 berjumlah 42 orang (100 \%) dan tidak ada yang menjawab "tidak." Ini artinya semua responden merasa senang dan bertumbuh lewat pelayanan pemuridan KEKAL yang dibuat oleh Gereja Baptis Anugerah Pontianak.

\section{KESIMPULAN}

Kedewasaan rohani orang Kristen adalah suatu kondisi yang harus menjadi perhatian bagi gereja, karena Alkitab sendiri sangat menekankan pentingnya pertumbuhan rohani para murid Kristus. Oleh sebab itu, gereja harus memperhatikan pertumbuhan rohani jemaatnya. Pemuridan KEKAL adalah salah satu program Gereja Baptis Anugerah Pontianak yang bertujuan untuk menumbuhkembangkan kehidupan rohani jemaat agar semakin dewasa di dalam Kristus.

Berdasarkan hasil penelitian, ditemukan bahwa program pemuridan KEKAL berperan secara efektif dalam membimbing gereja menuju kedewasaan baik secara kuantitas (pertambahan 
jemaat) maupun secara kualitas (hidup rohani). $\mathrm{Hal}$ ini terlihat dari jawaban responden terhadap semua pertanyaan tentang pemuridan KEKAL dan kedewasaan rohani.

Dari 8 pertanyaan yang berkaitan dengan pemuridan KEKAL, jawaban seluruh responden sangat positif. Mereka menyadari bahwa dirinya adalah murid Kristus yang harus terus bertumbuh dewasa secara rohani. Melalui pemuridan KEKAL jemaat menyadari perlunya bimbingan rohani dan bimbingan ini didapati dalam pemuridan KEKAL. Melalui pemuridan KEKAL jemaat merasakan pertumbuhan secara pengetahuan Alkitab dan kehidupan rohani melalui kesadaran akan pentingnya bertekun dalam pengajaran firman Tuhan, doa, kesaksian, kerelaan berkorban, mengasihi jiwa-jiwa, beriman, kesediaan berkorban, dan memiliki karakter Kristus. Dengan kesadaran akan manfaat pemuridan KEKAL, jemaat berkomitmen untuk mendukung program tersebut secara waktu, tenaga, dan dana.

Adapun dari 8 pertanyaan yang berkaitan dengan kedewasaan rohani, jawaban seluruh responden juga sangat positif. Jemaat merasa rindu untuk terus bertumbuh secara rohani. Mereka menyadari bahwa untuk bertumbuh dewasa secara rohani perlu bergauk dengan firman Tuhan, terus memelihara persekutuan dengan Allah, dan mempraktekkan firman Tuhan dengan setia melalui hidup dalam kasih dan kejujuran. Jemaat menyadari bahwa melalui pemuridan KEKAL, dirinya sedang bertumbuh semakin dewasa secara rohani.

Jadi, strategi pelayanan pemuridan melalui kelompok kecil efektif dalam membimbing orang Kristen untuk terus bertumbuh secara rohani dan berperan dalam fungsinya sebagai orang percaya. Diharapkan pemuridan dengan sistem kelompok kecil ini dapat menjadi salah satu strategi bagi gereja untuk membimbing anggota jemaat agar dewasa di dalam Kristus.

\section{KEPUSTAKAAN}

Autrey, Jerry. Surat Kiriman Penjara. Malang: Gandum Mas, t.t.

Benson, Warren S. Pedoman Lengkap untuk Kaum Muda. Bandung: Kalam Hidup, 1999.

Eims, LeRoy. Pemuridan Seni yang Hilang Bandung: Lembaga Literatur Baptis, 1978

Fances, Eddy. Mengenal dan dikenal Allah. Jakarta: Yasinta, 2003.

Griffiths, Michael. Gereja dan Panggilannya Dewasa Ini. Jakarta: BPK Gunung Mulia, 1991.

Hadiwijono, Harun. Iman Kristen. Jakarta: BPK Gunung Mulia, 2007.

Howard, Rick C. Pendewasaan Kristen. Malang: Gandum Mas, 1982.

Leo, Eddy. Murid Sejati: Suatu Pilihan Mutlak. Jakarta: Metanoia, 2005.

Liauw, Suhento. Doktrin Alkitab Alkitabiah. Jakarta: GBII GRAPHE, 1997.

Long, Jimmy. Buku Pegangan Pemimpin Kelompok Kecil. Jakarta: PERKANTAS, 1994.

McDermott, Gerald R. Mengenal 12 Tanda Kerohanian Sejati. Yogyakarta: ANDI 2001.

Nee, Wactman. Pekerja Kristus. Bandung: Kalam Hidup, 1972.

Robertson, Roy. Pemuridan dengan Prinsip Timotius. Yogyakarta: 1995.

Ryrie, Charles C. Teologi Dasar 2. Yogyakarta: Yayasan ANDI, 1992.

Sanders, J. Oswald. Kemuridan Rohani. Batam Center: Gospel Press, 2002.

Santoso, Arif, Lazarus L. ST. Toenioe dan Soleman ND, AYI. The God Way Handbook, t.t.

Setiawan, Obaja T. Kelompok Sel: Prinsip 12. Jakarta: Metanoia, t.t.

Wagner, J. Peter. Gereja Yang Berdoa. Yogyakarta: ANDI, 1993.

Ward, Charles G. Buku Pegangan Pelayanan. Jakarta: Persekutuan Pembaca Alkitab, 1995.

Warren, Rick. The Purpose Driven Life. Malang: Gandus Mas, 2005. 
Welong, Ronny. Program Pelayanan Gereja Baptis Anugerah Pontianak 2005-2010. Pontianak:

GB. Anugerah, 2005-2010.

Wiersbe, Warren W. Kaya di dalam Kristus.

Malang: Gandum Mas, 1982. 